\title{
Effect of dexmedetomidine anesthesia on respiratory function in pediatric patients undergoing retinoblastoma resection
}

\author{
XI RONG ${ }^{1,2^{*}}$, CHUNLEI SUN ${ }^{3 *}$, FENG ZHANG $^{2}$ and JIE ZHENG ${ }^{1}$ \\ ${ }^{1}$ School of Pharmacy of Qingdao University, Qingdao, Shandong 266021; Departments of ${ }^{2}$ Pharmacy and \\ ${ }^{3}$ Pediatric Internal Medicine, Yidu Central Hospital of Weifang, Weifang, Shandong 262500, P.R. China
}

Received September 5, 2018; Accepted December 18, 2018

DOI: $10.3892 / \mathrm{ol} .2019 .9893$

\begin{abstract}
The aim of this study was to investigate the effect of dexmedetomidine (Dex) on the respiratory function during anesthesia induction in pediatric patients undergoing retinoblastoma (RB) resection. A total of 87 pediatric patients who underwent RB resection in Yidu Central Hospital of Weifang were recruited into this study. General anesthesia was first induced for all patients, of which 45 were randomly assigned to the experimental group and received Dex through an intravenous infusion pump to maintain general anesthesia. The remaining 42 patients were assigned to the control group and received saline through an intravenous infusion pump. Respiratory function and hemodynamic indexes at five timepoints, i.e., before anesthesia induction (T0), $5 \mathrm{~min}$ after injection of anesthetic agents (T1), before intubation (T2), 15 min after intubation (T3), and 30 min after extubation (T4), were recorded and compared. Incidence of perioperative cardiac and respiratory adverse events was counted in both groups, and post-anesthesia resuscitation was evaluated and compared. Compared with $\mathrm{T} 0$, the respiratory rate $(\mathrm{R})$ of the experimental group was lower at T1-T4, but there was no statistical difference $(\mathrm{P}<0.05)$. Compared with $\mathrm{T} 0$, the control group had a higher $\mathrm{R}$ at $\mathrm{T} 2$, lower $\mathrm{R}$ at $\mathrm{T} 3$ and $\mathrm{T} 4(\mathrm{P}<0.05)$, and there was no significant difference in $\mathrm{R}$ between $\mathrm{T} 0$ and $\mathrm{T} 1$ ( $\mathrm{P}>0.05)$. At the same time-point, compared with the experimental group, the $\mathrm{R}$ was higher at $\mathrm{T} 2$, and lower at $\mathrm{T} 3$ and T4 in the control group $(\mathrm{P}<0.05)$, and no significant difference was found at T1. Blood oxygen saturation $\left(\mathrm{SpO}_{2}\right)$ of the experimental group was slightly lower than that of $\mathrm{T} 0$ at T1-T4 $(\mathrm{P}>0.05)$. In the control group, the levels of $\mathrm{SpO}_{2}$ were significantly lower at $\mathrm{T} 1-\mathrm{T} 4$ than those at $\mathrm{T} 0(\mathrm{P}<0.05)$. Compared with the experimental group at the same time-point,
\end{abstract}

Correspondence to: Dr Jie Zheng, School of Pharmacy of Qingdao University, 38 Dengzhou Road, Qingdao, Shandong 266021, P.R. China

E-mail: jzh9qz@163.com

*Contributed equally

Key words: dexmedetomidine, retinoblastoma resection, anesthesia induction, respiratory function, hemodynamics
$\mathrm{SpO}_{2}$ of the control group at T1-T4 decreased significantly $(\mathrm{P}<0.05)$. The heart rate $(\mathrm{HR})$ of the experimental and control groups was lower at T1-T4 than that at T0 $(\mathrm{P}<0.05)$. The HR of the experimental group was higher than that of the control group at T1-T4 $(\mathrm{P}<0.05)$. Mean arterial pressure $(\mathrm{MAP})$ of the experimental and control groups was lower at T1-T4 than that at T0 $(\mathrm{P}<0.05)$. MAP of the control group was higher than that of the experimental group at $\mathrm{T} 2$ but lower than that at $\mathrm{T} 0$ of the control group. MAP of the control group was lower than that of the experimental group at T1-T4. There was no significant difference in incidence of tachycardia, bradycardia, vomiting, hypoxia and laryngism between the two groups $(\mathrm{P}>0.05)$. There was no difference in resuscitation and extubation time between the two groups $(\mathrm{P}>0.05)$. Finally, agitation of the control group was more severe than that of the experimental group $(\mathrm{P}<0.05)$. Therefore, Dex can improve the respiratory function and hemodynamic stability during anesthesia induction in children with $\mathrm{RB}$ resection.

\section{Introduction}

Retinoblastoma (RB) is the most common ocular malignancy in infants and young children (1). Incidence of RB ranks second among all malignancies that occur in infants and young children. At present, the global incidence is about 1x6,000, and the number of new cases is about 5,000 per year (2). Statistics show that about $90 \%$ RB occurred before the age of 6 , and more than $60 \%$ RB was monocular (3). In addition, the incidence was constant across race and region (4). RB seriously affects children's vision and even threatens their life. The key of the survival of RB patients is early diagnosis and timely effective treatment (5). According to literature, most patients with RB in China were diagnosed at advanced stages and the best time for non-surgical treatment is usually missed (6). However, the most common and effective treatment in clinical practice is surgical removal of diseased eyeballs (7).

\section{Materials and methods}

Since the internal organs of infants and young children are at the stage of growth and development, the functions of various systems are still immature. For example, they have a weak immune system and low sense of autonomy as well as ability to process outside information (8). According to literature, safety 
risks of general anesthesia in children undergoing surgery are much greater than in adults (9). Anesthetic agents have a pronounced impact on respiratory function in children. When children are sedated, their small airways are prone to collapse. Small airway closure leads to low lung ventilation, and children are prone to intraoperative complications such as cough, airway obstruction and even asphyxia (10). It was reported that dexmedetomidine (Dex) has strong calming and anti-anxiety effects while lacking respiratory depressant effects. It causes few adverse reactions, including a light impact on circulatory system. Dex is an excellent sedative and hypnotic drug and has been widely used in clinical anesthesia (11). To the best of our knowledge, there is no previous report on the effect of Dex on the respiratory system in pediatric patients undergoing RB surgical resection. This study aimed to investigate whether Dex can stabilize the respiratory function in perioperative children and can avoid complications such as arrhythmia and hypoxia caused by the surgical procedure.

Subjects. A total of 87 pediatric patients who underwent RB resection were recruited into this study. General anesthesia was first induced for all patients, of which 45 were randomly assigned to the experimental group and received Dex through an intravenous infusion pump to maintain general anesthesia. In the experimental group, there were 24 males and 21 females, aged $1-8$ years, with a mean age of $4.37 \pm 0.78$ years. The remaining 42 patients were assigned to the control group and received saline through an intravenous infusion pump. In the control group, there were 22 males and 20 females, aged 1-8 years, with a mean age of $4.41 \pm 0.82$ years. The general clinical records are shown in Table I.

Patients who met the following criteria were eligible for this study: i) patients who were assigned Class I or Class II according to American Society of Anesthesiologists (ASA) physical status classification (12); ii) patients who were diagnosed with RB by fundus examination and imaging tests such as B-ultrasound; and iii) patients who were assigned D-E phase, extraocular phase, and metastasis phase according to International Intraocular Retinoblastoma Classification (IIRC) (12), or patients who had extraocular RB or metastatic $\mathrm{RB}$ and experienced severe eye pain and whose lesioned eyeballs had no chance for recovery of vision. This study was approved by the Medical Ethics Committee of Yidu Central Hospital of Weifang (Weifang, China). Patients' families were informed of the specific contents of the study and signed a completed informed consent form.

Patients who met the following criteria were excluded from the study: i) patients who suffered from primary disease affecting their respiratory function, such as bronchial asthma and myasthenia gravis; ii) patients who had cardiopulmonary disorders or liver/kidney dysfunction, associated with serious infection; and iii) patients who had obvious surgical contraindications such as coagulation disorders and allergy to anesthetic agents.

\section{Methods}

Pharmaceutical drugs and instruments. Pharmaceutical drugs used in this study were purchased from various sources: atropine sulfate injection [SFDA Approval no. H41021817; Kaifeng Pharmaceutical (Group) Co., Ltd., Kaifeng, China], phenobarbital tablets (SFDA Approval no. H61021669; Xi'an
Lijun Pharmaceutical Co., Ltd., Xi'an, China), lidocaine hydrochloride injection (SFDA Approval no. H45020823; Guilin Pharmaceutical Co., Ltd., Guilin, China), sufentanil citrate injection (SFDA Approval no. H20054172; Yichang Humanwell Pharmaceutical Co., Ltd., Yichang, China), propofol injection (SFDA Approval no. H20123138; Jiangsu Nhwa Pharmaceutical Co.,Ltd., Jiangsu, China) and Dex (SFDA Approval no. H20110086; Jiangsu Nhwa Pharmaceutical Co., Ltd.), midazolam (SFDA Approval no. ZWK-135-13791; Shanghai ZZBio Co., Ltd., Shanghai, China), and cisatracurium besylate [SFDA Approval no. H20060926; DongYing (Jiangsu) Pharmaceutical Co., Ltd., Jiangsu, China]. The following instruments were purchased from respective sources: the ECG monitor (Article no. 6800-10; Shanghai Zhiheng Medical Devices Co., Ltd., Shanghai, China) the tracheal intubation catheter (Article no. TK8976; Henan Zeyuan Medical Equipment Sales Co., Ltd., Beijing, China, http://www.tdshoupin.com/) and the anesthesia machine (Article no. 06; Beijing First Product Condar Technology Co., Ltd., Beijing, China).

Anesthetic procedures. All pediatric patients underwent 8-12 h fasting and water-deprivation before surgery. Atropine sulfate $(0.01 \mathrm{mg} / \mathrm{kg})$ and phenobarbital tablets $(2-3 \mathrm{mg} / \mathrm{kg})$ were given via routine injection and oral administration, respectively, $30 \mathrm{~min}$ before entering the operating room to achieve preoperative stabilization. After the child entered the operating room, the surgical site was routinely disinfected before surgery. After performing local infiltration anesthesia by injection of $1 \%$ lidocaine, an indwelling catheter was placed on the right hand through radial artery puncture, followed by establishment of a venous access. Patients were then connected to an ECG monitor. A general anesthesia protocol was developed after assessment of the patient's overall physical state. The patient was gently pacified before anesthesia.

General anesthesia was induced for all subjects by intravenous injection of fentanyl (2.0-3.5 $\mu \mathrm{g} / \mathrm{kg})$, propofol $(1.0-1.5 \mathrm{mg} / \mathrm{kg})$, midazolam $(0.05 \mathrm{mg} / \mathrm{kg})$, and atracurium $(0.5-0.8 \mathrm{mg} / \mathrm{kg})$. During the same time, patients in the experimental group were given Dex $(1 \mu \mathrm{g} / \mathrm{kg})$ through an intravenous infusion pump at a rate of $0.2-0.8 \mu \mathrm{g} /(\mathrm{kg} \cdot \mathrm{h})$ within $15 \mathrm{~min}$, and patients in the control group received $0.9 \%$ saline $(0.25 \mathrm{ml} / \mathrm{kg})$ as a reference, through an intravenous infusion pump at a rate of $0.125 \mathrm{ml} /(\mathrm{kg} \cdot \mathrm{h})$ within $15 \mathrm{~min}$. After sufficient anesthetic depth was reached, tracheal intubation was performed to assist breathing using a catheter for age +18 . After that, patient were connected to an anesthesia machine for breathing control. If the child still maintained spontaneous breathing function, expansion and contraction of the respiratory balloon, it could be seen with the breath. If spontaneous breathing was not observed, the anesthesia machine was then adjusted to provide a tidal volume of $14-20 \mathrm{ml} / \mathrm{kg}$, a respiratory rate $(\mathrm{R})$ of 20-30 breaths/min, an inspiration-to-expiration ratio (I:E) of 1:2, and an end-tidal $\mathrm{CO}_{2}$ partial pressure of 35-40 $\mathrm{mmHg}$. During the operation, patients were checked regularly for a normal breath sound and a respiratory undulation of the chest.

Observed indicators. i) Indexes of respiratory function and hemodynamics at five time-points, i.e., before anesthesia induction (T0), 5 min after injection of anesthetic agents (T1), 
Table I. General clinical record (mean \pm standard deviation) [n (\%)].

\begin{tabular}{|c|c|c|c|c|}
\hline Variables & $\begin{array}{l}\text { Experimental group } \\
n=45\end{array}$ & $\begin{array}{l}\text { Control group } \\
n=42\end{array}$ & t or $\chi^{2}$ & P-value \\
\hline Age (year) & $4.37 \pm 0.78$ & $4.41 \pm 0.82$ & 0.233 & 0.816 \\
\hline Body weight (kg) & $8.59 \pm 5.37$ & $8.72 \pm 4.83$ & 0.118 & 0.906 \\
\hline \multicolumn{5}{|l|}{ Sex } \\
\hline Male & $24(53.33)$ & $22(52.38)$ & \multirow[t]{2}{*}{0.008} & \multirow[t]{2}{*}{0.929} \\
\hline Female & $21(46.67)$ & $20(47.62)$ & & \\
\hline \multicolumn{5}{|l|}{ ASA classification } \\
\hline Class I & $28(62.22)$ & $26(61.90)$ & \multirow[t]{2}{*}{0.001} & \multirow[t]{2}{*}{0.976} \\
\hline Class II & 17 (37.78) & $16(38.10)$ & & \\
\hline \multicolumn{5}{|l|}{ Clinical stage } \\
\hline Group D & $21(46.67)$ & $18(42.86)$ & \multirow[t]{4}{*}{0.470} & \multirow[t]{4}{*}{0.926} \\
\hline Group E & $12(26.67)$ & $14(33.33)$ & & \\
\hline Extraocular RB & $7(15.56)$ & $6(14.29)$ & & \\
\hline Metastatic RB & $5(11.11)$ & $4(9.52)$ & & \\
\hline \multicolumn{5}{|l|}{ Clinical manifestation } \\
\hline Strabismus & $5(11.11)$ & $5(11.90)$ & \multirow[t]{4}{*}{0.077} & \multirow[t]{4}{*}{0.995} \\
\hline White pupillary reflex & $30(66.67)$ & $28(66.67)$ & & \\
\hline Vision problem & $5(11.11)$ & $5(11.90)$ & & \\
\hline Eye congestion & $5(11.11)$ & $4(9.52)$ & & \\
\hline \multicolumn{5}{|l|}{ Affected eye } \\
\hline Left eye & $17(37.78)$ & $15(35.71)$ & \multirow[t]{3}{*}{0.054} & \multirow[t]{3}{*}{0.973} \\
\hline Right eye & $16(35.55)$ & $15(35.71)$ & & \\
\hline Bilateral & $12(26.67)$ & $12(28.57)$ & & \\
\hline \multicolumn{5}{|c|}{$\begin{array}{l}\text { Three generations of } \\
\text { immediate family members } \\
\text { with RB }\end{array}$} \\
\hline Yes & 13 (28.89) & $11(26.19)$ & \multirow[t]{2}{*}{0.079} & \multirow[t]{2}{*}{0.778} \\
\hline No & $32(71.11)$ & $31(73.81)$ & & \\
\hline
\end{tabular}

before intubation (T2), $15 \mathrm{~min}$ after intubation (T3), and $30 \mathrm{~min}$ after extubation (T4), were recorded for all subjects. The indexes of respiratory function included $\mathrm{R}$ and blood oxygen saturation $\left(\mathrm{SpO}_{2}\right)$ value. The intraoperative hemodynamic indexes included heart rate (HR) and mean arterial pressure (MAP) value. ii) Incidence of perioperative cardiac and respiratory adverse events in both groups was recorded: cardiac arrest, apnea, bradycardia (HR was more than $30 \%$ lower than healthy children of the age group), tachycardia (HR was more than $30 \%$ higher than healthy children of the age group), vomiting, hypoxia $\left(\mathrm{SpO}_{2}<90 \%\right.$ at the end of $\left.60 \mathrm{sec}\right)$, and laryngism $(13,14)$. iii) Postoperative anesthesia recovery of the experimental and control groups was recorded in detail: recovery time of anesthesia (the time between discontinuation of intravenous anesthesia in the two groups to the blink of children) and the time of extubation (the time between discontinuation of intravenous anesthesia and organ catheter extraction). Agitation score (PAED) (15) was used to evaluate the postoperative agitation.

Statistical analysis. Statistical analysis was performed using SPSS 19.0 statistics software system (IBM SPSS, Shanghai,
China). Measurement data were expressed as mean \pm standard deviation. The t-test was used for comparison between the two groups. Repeated measures ANOVA and Least Significant Difference post hoc test were used for comparison between multiple groups. Enumeration data were expressed in percentage (\%). The $\chi^{2}$ test was used for the analysis of count data. $\mathrm{P}<0.05$ was considered to indicate a statistically significant difference.

\section{Results}

General clinical record. As shown in Table I, there were no significant differences in sex, age, and ASA classification between the experimental and control groups $(\mathrm{P}>0.05)$.

Respiratory rate (breaths/min) at different time-points. Regarding the comparison of $\mathrm{R}$, there was no difference among T0-T4 in the experimental group $(\mathrm{P}>0.05)$; there were differences among T0-T4 in the control group $(\mathrm{P}<0.05)$. Compared with T0, the control group had a lower R at T2-T4 $(\mathrm{P}<0.05)$. Compared with T1, the control group had a lower R at T2-T4 $(\mathrm{P}<0.05)$. Compared with $\mathrm{T} 2$, the control group had a lower $\mathrm{R}$ 
Table II. Respiratory rate (breaths/min) at different time-points.

\begin{tabular}{|c|c|c|c|c|}
\hline Time-points & Experimental group & Control group & $\mathrm{t}$ & P-value \\
\hline T0 & $23.36 \pm 3.86$ & $23.42 \pm 3.78$ & 0.073 & 0.942 \\
\hline $\mathrm{T} 1$ & $23.28 \pm 3.97$ & $21.83 \pm 2.86$ & 0.535 & 0.5938 \\
\hline $\mathrm{T} 2$ & $22.67 \pm 4.24$ & $25.46 \pm 3.35^{\mathrm{a}, \mathrm{b}}$ & 3.389 & 0.001 \\
\hline $\mathrm{T} 3$ & $23.32 \pm 4.15$ & $18.68 \pm 2.13^{\mathrm{a}-\mathrm{c}}$ & 6.490 & $<0.001$ \\
\hline $\mathrm{T} 4$ & $22.74 \pm 4.17$ & $19.24 \pm 2.54^{\mathrm{a}-\mathrm{c}}$ & 4.687 & $<0.001$ \\
\hline $\mathrm{F}_{\text {group }}$ & 8.298 & - & - & - \\
\hline $\mathrm{P}_{\text {group }}$ & $<0.001$ & - & - & - \\
\hline $\mathrm{F}_{\text {intercross }}$ & 21.311 & - & - & - \\
\hline$P_{\text {intercross }}$ & $<0.001$ & - & - & - \\
\hline
\end{tabular}

${ }^{\mathrm{a}} \mathrm{P}<0.05$, compared with $\mathrm{T} 0$ in the control group; ${ }^{\mathrm{b}}<0.05$, compared with $\mathrm{T} 1$ in the control group; ${ }^{\mathrm{C}}<0.05$, compared with $\mathrm{T} 2$ in the control group.

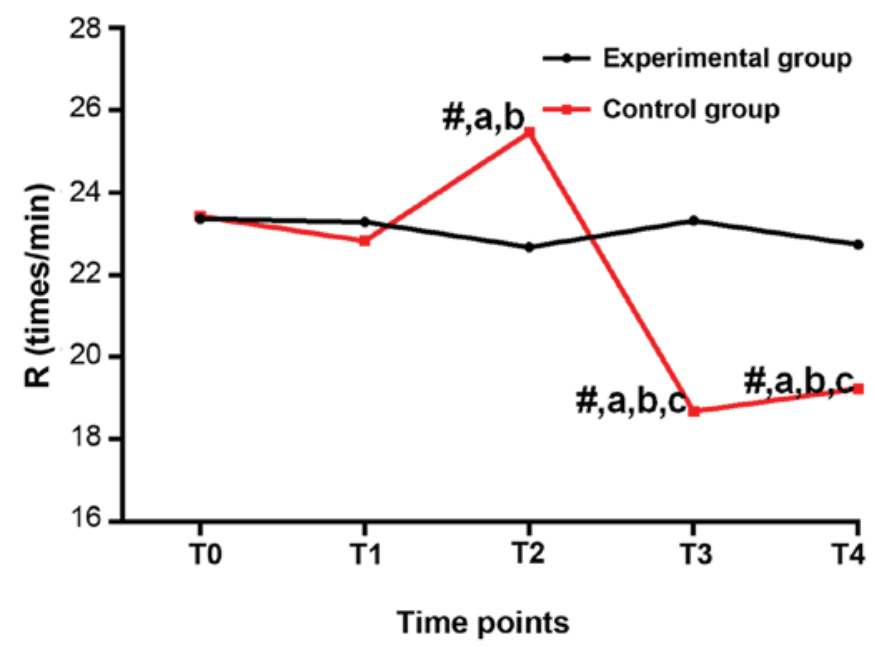

Figure 1. Respiratory rate (breaths/min) at different time-points. There were no significant differences in $\mathrm{R}$ value between different time-points in the experimental group $(\mathrm{P}>0.05)$. In the control group, compared with $\mathrm{T} 0$ and $\mathrm{T} 1$, the $\mathrm{R}$ values were lower from $\mathrm{T} 2$ to $\mathrm{T} 4(\mathrm{P}<0.05)$; compared with $\mathrm{T} 2$, the $R$ values were lower from $\mathrm{T} 3$ to $\mathrm{T} 4(\mathrm{P}<0.05)$. In the in-between-group comparison, the $\mathrm{R}$ values were comparable at T0 and T1 ( $\mathrm{P}>0.05)$, lower at $\mathrm{T} 2$ and higher from T3 to T4 $(\mathrm{P}<0.05)$ in the experimental group. ${ }^{*} \mathrm{P}<0.05$, compared with the same time-point in the experimental group; ${ }^{\text {a }} \mathrm{P}<0.05$, compared with $\mathrm{T} 0$ in the control group; ${ }^{\mathrm{b}} \mathrm{P}<0.05$, compared with $\mathrm{T} 1$ in the control group; ${ }^{\mathrm{P}} \mathrm{P}<0.05$, compared with $\mathrm{T} 2$ in the control group.

at $\mathrm{T} 3$ and $\mathrm{T} 4(\mathrm{P}<0.05)$. Compared with the experimental group at the same time-point, $\mathrm{R}$ was higher at $\mathrm{T} 2$, and lower at $\mathrm{T} 3$ and $\mathrm{T} 4$ in the control group $(\mathrm{P}<0.05)$, and no significant difference was found at T0 and T1 ( $\mathrm{P}>0.05$; Table II and Fig. 1).

Blood oxygen saturation $\left(\mathrm{SpO}_{2}\right)(\%)$ at different time-points. $\mathrm{SpO}_{2}$ of the experimental group was slightly lower than that of T0 at T1-T4 $(\mathrm{P}>0.05)$. Compared with $\mathrm{T} 1, \mathrm{SpO}_{2}$ of the experimental group decreased significantly at $\mathrm{T} 3(\mathrm{P}<0.05)$. Compared with $\mathrm{T} 2, \mathrm{SpO}_{2}$ of the experimental group decreased significantly at $\mathrm{T} 3(\mathrm{P}<0.05)$. Compared with $\mathrm{T} 3, \mathrm{SpO}_{2}$ of the experimental group decreased significantly at $\mathrm{T} 4(\mathrm{P}<0.05)$. In the control group, levels of $\mathrm{SpO}_{2}$ were significantly lower at T1-T4 than that at T0 $(\mathrm{P}<0.05)$. Compared with the experimental group at the same time-point, $\mathrm{SpO}_{2}$ of the control group at T1-T4 decreased significantly $(\mathrm{P}<0.05)$. Compared with $\mathrm{T} 2, \mathrm{SpO}_{2}$ of the control group decreased significantly at $\mathrm{T} 3(\mathrm{P}<0.05)$. Compared with $\mathrm{T} 3, \mathrm{SpO}_{2}$ of the control group decreased significantly at $\mathrm{T} 4(\mathrm{P}<0.05)$. Compared with the experimental group at the same time-point, $\mathrm{SpO}_{2}$ of the control group decreased significantly at T1-T4 $(\mathrm{P}<0.05)$, and there was no significant difference between the two groups at T0 (P>0.05; Table III and Fig. 2).

HR (beats per minute) at different time-points. HR of the experimental group were lower at T3 and T4 than that at T0 $(\mathrm{P}<0.05)$. HR of the experimental and control groups were lower at T1-T4 than that at T0 $(\mathrm{P}<0.05)$. HR of the experimental group was higher than that of the control group at T1-T4 ( $\mathrm{P}<0.05)$. Compared with T1, HR of the control group decreased significantly at $\mathrm{T} 3$ and $\mathrm{T} 4(\mathrm{P}<0.05)$. Compared with $\mathrm{T} 2$, HR of the control group decreased significantly at T4 $(\mathrm{P}<0.05)$. HR was higher in the experimental group than in the control group at T2-T4 $(\mathrm{P}<0.05)$, but no significant differences were found at T0 and T1 ( $\mathrm{P}>0.05$; Table IV and Fig. 3).

MAP ( $\mathrm{mmHg}$ ) at different time-points. As shown in Table V, MAP of the experimental and control groups were lower at T1-T4 than that at T0 $(\mathrm{P}<0.05)$. Compared with T1, MAP of the experimental group decreased at $\mathrm{T} 3$ and $\mathrm{T} 4(\mathrm{P}<0.05)$. Compared with T1, MAP of the control group decreased at T2-T4 ( $\mathrm{P}<0.05)$. Compared with T2, MAP of the control group decreased at T3 and T4 $(\mathrm{P}<0.05)$. MAP of the control group was higher than that of the experimental group at $\mathrm{T} 2$ but lower than that of the experimental group at T1-T4, no significant differences were found at T0 (Fig. 4).

Post-anesthesia recovery in the two groups of children. The recovery time of the experimental and control groups were $8.37 \pm 4.93$ and $8.63 \pm 4.74 \mathrm{~min}$, respectively. There was no significant difference between the two groups $(\mathrm{P}>0.05)$. The extubation time of the two groups was $10.48 \pm 4.72$ and $10.74 \pm 4.13 \mathrm{~min}$, respectively. There was no difference in the extubation time between the two groups $(\mathrm{P}>0.05)$. Agitation scores of the two groups were $1.52 \pm 0.63$ and $3.74 \pm 0.45$, respectively. Agitation was more 
Table III. Blood oxygen saturation (\%) at different time-points.

\begin{tabular}{|c|c|c|c|c|}
\hline Time-points & Experimental group & Control group & $\mathrm{t}$ & P-value \\
\hline T0 & $98.42 \pm 0.35$ & $98.36 \pm 0.41$ & 0.736 & 0.464 \\
\hline $\mathrm{T} 1$ & $98.36 \pm 0.29$ & $97.34 \pm 0.26^{\mathrm{e}}$ & 17.230 & $<0.001$ \\
\hline $\mathrm{T} 2$ & $98.28 \pm 0.37$ & $94.93 \pm 0.14^{\mathrm{e}, \mathrm{f}}$ & 55.090 & $<0.001$ \\
\hline $\mathrm{T} 3$ & $97.94 \pm 0.83^{\mathrm{a}-\mathrm{c}}$ & $96.15 \pm 0.21^{\mathrm{e}-\mathrm{g}}$ & 13.570 & $<0.001$ \\
\hline $\mathrm{T} 4$ & $98.32 \pm 0.44^{\mathrm{d}}$ & $95.02 \pm 0.14^{\mathrm{e}, \mathrm{fh}}$ & 46.450 & $<0.001$ \\
\hline $\mathrm{F}_{\text {group }}$ & 82.000 & - & - & - \\
\hline $\mathrm{P}_{\text {group }}$ & $<0.001$ & - & - & - \\
\hline $\mathrm{F}_{\text {intercross }}$ & 82.000 & - & - & - \\
\hline$P_{\text {intercross }}$ & $<0.001$ & - & - & - \\
\hline
\end{tabular}

${ }^{\mathrm{a}} \mathrm{P}<0.05$, compared with $\mathrm{T} 0$ in the experimental group; ${ }^{\mathrm{b}} \mathrm{P}<0.05$, compared with $\mathrm{T} 1$ in the experimental group; ${ }^{\mathrm{c}} \mathrm{P}<0.05$, compared with $\mathrm{T} 2$ in the experimental group; ${ }^{\mathrm{d}} \mathrm{P}<0.05$, compared with $\mathrm{T} 3$ in the experimental group; ${ }^{\mathrm{e}} \mathrm{P}<0.05$, compared with $\mathrm{T} 0$ in the control group; ${ }^{\mathrm{f}} \mathrm{P}<0.05$, compared with $\mathrm{T} 1$ in the control group; ${ }^{\mathrm{g}} \mathrm{P}<0.05$, compared with $\mathrm{T} 2$ in the control group; and ${ }^{\mathrm{h}} \mathrm{P}<0.05$, compared with $\mathrm{T} 3$ in the control group.

Table IV. Heart rates (beats/min) at different time-points.

\begin{tabular}{|c|c|c|c|c|}
\hline Time-points & Experimental group & Control group & $\mathrm{t}$ & P-value \\
\hline T0 & $127.52 \pm 8.74$ & $126.94 \pm 8.56$ & 0.312 & 0.756 \\
\hline $\mathrm{T} 1$ & $123.52 \pm 7.36$ & $121.43 \pm 6.35^{\mathrm{b}}$ & 1.414 & 0.161 \\
\hline $\mathrm{T} 2$ & $123.45 \pm 7.42$ & $118.93 \pm 6.14^{\mathrm{b}}$ & 3.083 & 0.003 \\
\hline $\mathrm{T} 3$ & $122.25 \pm 7.38^{\mathrm{a}}$ & $116.25 \pm 5.21^{\mathrm{b}, \mathrm{c}}$ & 5.078 & $<0.001$ \\
\hline $\mathrm{T} 4$ & $122.12 \pm 7.25^{\mathrm{a}}$ & $114.02 \pm 5.15^{\mathrm{b}-\mathrm{d}}$ & 5.969 & $<0.001$ \\
\hline $\mathrm{F}_{\text {group }}$ & 27.461 & - & - & - \\
\hline $\mathrm{P}_{\text {group }}$ & $<0.001$ & - & - & - \\
\hline $\mathrm{F}_{\text {intercross }}$ & 1.528 & - & - & - \\
\hline$P_{\text {intercross }}$ & 0.199 & - & - & - \\
\hline
\end{tabular}

${ }^{\mathrm{a}} \mathrm{P}<0.05$, compared with $\mathrm{T} 0$ in the experimental group; ${ }^{\mathrm{b}} \mathrm{P}<0.05$, compared with $\mathrm{T} 0$ in the control group; ${ }^{\mathrm{C}}<0.05$, compared with $\mathrm{T} 1$ in the control group; ${ }^{\mathrm{d}} \mathrm{P}<0.05$, compared with $\mathrm{T} 2$ in the control group.

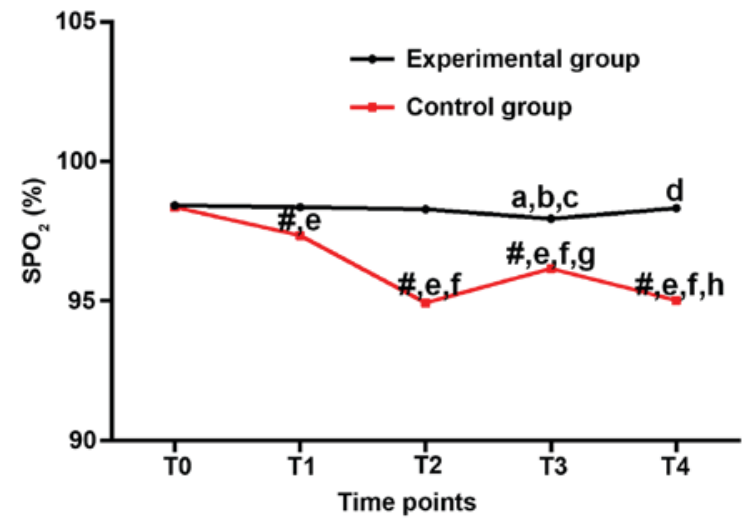

Figure 2. Blood oxygen saturation (\%) at different time-points. In the experimental group, the differences in $\mathrm{SpO}_{2}$ value were not statistically significant across the time-points $(\mathrm{P}>0.05)$. In between-group comparison, the $\mathrm{SpO}_{2}$ values were all higher in the experimental group, and the difference at $\mathrm{T} 2$ was statistically significant $(\mathrm{P}<0.05)$. ${ }^{\text {"P }}<0.05$, compared with the same time-point in the experimental group; ${ }^{\text {a }} \mathrm{P}<0.05$, compared with $\mathrm{T} 0$ in the experimental group; ${ }^{b} \mathrm{P}<0.05$, compared with $\mathrm{T} 1$ in the experimental group; ${ }^{\mathrm{c}} \mathrm{P}<0.05$, compared with $\mathrm{T} 2$ in the experimental group; ${ }^{\mathrm{d}} \mathrm{P}<0.05$, compared with $\mathrm{T} 3$ in the experimental group; ${ }^{\mathrm{e}} \mathrm{P}<0.05$, compared with $\mathrm{T} 0$ in the control group; ${ }^{\mathrm{f}} \mathrm{P}<0.05$, compared with $\mathrm{T} 1$ in the control group; ${ }^{\text {g }} \mathrm{P}<0.05$, compared with $\mathrm{T} 2$ in the control group; ${ }^{\mathrm{h}} \mathrm{P}<0.05$, compared with $\mathrm{T} 3$ in the control group. severe in the control group than in the experimental group $(\mathrm{P}<0.05$; Fig. 5).

\section{Discussion}

Since there is no universal screening for common eye diseases in newborns and preschool children in China, most RBs are diagnosed as advanced intraocular RB group D or above at diagnosis (16). Therefore, RB still poses a significant health threat to infants and young children in China. Currently, the clinical treatment of advanced RB is still the enucleation of the affected eyeball to avoid further progression of the disease (17). However, for infants and young children whose organ systems are not fully developed, conventional general anesthesia often has an inhibitory effect on respiratory function (18). For example, propofol is a widely used opioid analgesic in clinical practice with an excellent analgesic effect (19). However, propofol can decrease vagal tone, resulting in low extent of pulmonary expansion and collapse due to participation of vagus nerve in pulmonary stretch reflexes. Eventually the tidal volume decreases, and the respiratory function is suppressed (20). Another example is sufentanil, a 
Table V. Mean arterial pressure value $(\mathrm{mmHg})$ at different time-points.

\begin{tabular}{lcccr}
\hline Time-points & Experimental group & Control group & $\mathrm{t}$ & P-value \\
\hline T0 & $70.67 \pm 4.83$ & $71.02 \pm 4.26$ & 0.357 & 0.722 \\
T1 & $65.32 \pm 4.36^{\mathrm{a}}$ & $63.43 \pm 3.35^{\mathrm{c}}$ & 2.256 & 0.027 \\
T2 & $63.65 \pm 4.26^{\mathrm{a}}$ & $68.55 \pm 3.24^{\mathrm{c}, \mathrm{d}}$ & 6.006 & $<0.001$ \\
T3 & $62.25 \pm 4.72^{\mathrm{a}, \mathrm{b}}$ & $60.13 \pm 3.16^{\mathrm{c}-\mathrm{e}}$ & 2.444 & 0.017 \\
T4 & $62.12 \pm 4.23^{\mathrm{a}, \mathrm{b}}$ & $59.42 \pm 3.07^{\mathrm{ce}}$ & 3.387 & 0.001 \\
F & 27.790 & 65.820 & & \\
P-value & $<0.001$ & $<0.001$ & & \\
\hline
\end{tabular}

${ }^{\mathrm{a}} \mathrm{P}<0.05$, compared with $\mathrm{T} 0$ in the experimental group; ${ }^{\mathrm{b}} \mathrm{P}<0.05$, compared with $\mathrm{T} 1$ in the experimental group; ${ }^{\mathrm{c}} \mathrm{P}<0.05$, compared with $\mathrm{T} 0$ in the control group; ${ }^{\mathrm{d}} \mathrm{P}<0.05$, compared with $\mathrm{T} 1$ in the control group; ${ }^{\mathrm{e}} \mathrm{P}<0.05$, compared with $\mathrm{T} 2$ in the control group.

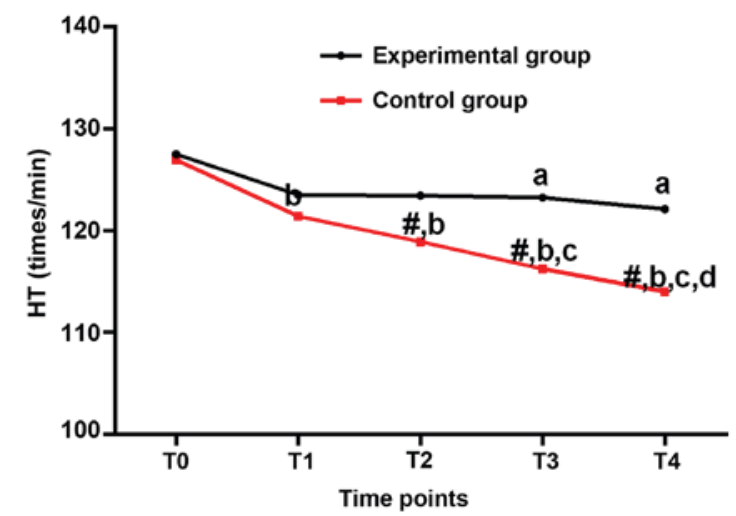

Figure 3. Heart rates (beats/min) at different time-points. In both the experimental and control groups, the HR values from T1 to T4 were all significantly lower compared with T0 $(\mathrm{P}<0.05)$. In the in-between-group comparison, the HR values were all higher in the experimental group, and the differences were statistically significant $(\mathrm{P}<0.05)$. ${ }^{\#} \mathrm{P}<0.05$, compared with the same time-point in the experimental group; ${ }^{a} \mathrm{P}<0.05$, compared with $\mathrm{T} 0$ in the experimental group; ${ }^{\mathrm{b}} \mathrm{P}<0.05$, compared with $\mathrm{T} 0$ in the control group; ${ }^{\mathrm{c}} \mathrm{P}<0.05$, compared with $\mathrm{T} 1$ in the control group; ${ }^{\mathrm{d}} \mathrm{P}<0.05$, compared with $\mathrm{T} 2$ in the control group.

strong opioid analgesic commonly used in clinical practice. It has the advantage of fast onset and short half-life (21). However, sufentanil has a strong affinity and selectivity for the $\mu$ receptors, which are distributed in the respiratory control center located in medulla oblongata, resulting in alterations in the heart rate and tidal volume. Eventually the respiratory function is affected (22).

Related studies showed that Dex is a highly selective $\alpha$ adrenergic receptor agonist. It has excellent anti-anxiety as well as strong analgesic and sedative effects (23). According to literature, Dex can reduce the output of sympathetic nerves by increasing the output of parasympathetic nerves, thereby inhibiting the activity of sympathetic nerves (24). The use of Dex during the surgical procedure, can reduce the fluctuation of hemodynamic parameters due to intraoperative events such as intubation, extubation, awakening and stress response, and also relieve the respiratory depression associated with the action of other drugs (25). To the best of our knowledge, there is no report in literature on the use of Dex in RB surgical resection and its effect on improving the respiratory function of pediatric patients with RB.

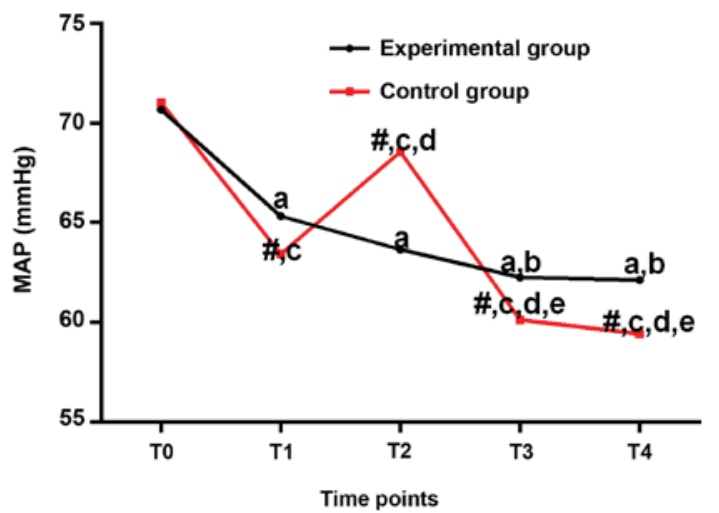

Figure 4. Mean arterial pressures $(\mathrm{mmHg})$ at different time-points. In the experimental group, the MAP values from T1 to T4 were all lower than that at T0 $(\mathrm{P}<0.05)$. In the in-between-group comparison, the MAP value was lower at T2 but higher at T1, T3 and T4 in the experimental group, and the differences were statistically significant $(\mathrm{P}<0.05) .{ }^{\#} \mathrm{P}<0.05$, compared with the same time-point in the experimental group; ${ }^{a} \mathrm{P}<0.05$, compared with $\mathrm{T} 0$ in the experimental group; ${ }^{b} \mathrm{P}<0.05$, compared with $\mathrm{T} 1$ in the experimental group; ${ }^{\mathrm{c}} \mathrm{P}<0.05$, compared with $\mathrm{T} 0$ in the control group; ${ }^{\mathrm{d}} \mathrm{P}<0.05$, compared with $\mathrm{T} 1$ in the control group; ${ }^{\mathrm{e}} \mathrm{P}<0.05$, compared with $\mathrm{T} 2$ in the control group.

There were no significant differences in sex, age and ASA classification between the two groups. Patients in the experimental group received Dex. Their heart rates from $\mathrm{T} 1$ to $\mathrm{T} 4$ were all slightly lower than that at $\mathrm{T} 0$, but the differences were not statistically significant. Patients in the control group received saline, and their heart rate at $\mathrm{T} 2$ was significantly higher than that at $\mathrm{T} 0(\mathrm{P}<0.05)$, but the heart rates at $\mathrm{T} 3$ and T4 were all significantly lower than that at $\mathrm{T} 0(\mathrm{P}<0.05)$. Overall changes in heart rate in the control group were larger than those in the experimental group. In terms of $\mathrm{SpO}_{2}$, values from $\mathrm{T} 1$ to $\mathrm{T} 4$ in the experimental group fluctuated slightly compared with that at $\mathrm{T} 0$, but the differences were not statistically significant $(\mathrm{P}>0.05)$. $\mathrm{SpO}_{2}$ values from $\mathrm{T} 1$ to $\mathrm{T} 4$ in the control group were significantly lower than that at $\mathrm{T} 0$ $(\mathrm{P}<0.05)$, which was consistent with a trend demonstrated by large fluctuations of respiratory indexes in the control group. The intense and repeated tracheal stimulation resulted from tracheal intubation may cause fluctuations in the respiratory indexes. In the experimental group, however, the difference in the respiratory index between time-points $\mathrm{T} 1$ and $\mathrm{T} 2$ was not statistically significant, which suggested that Dex had a 


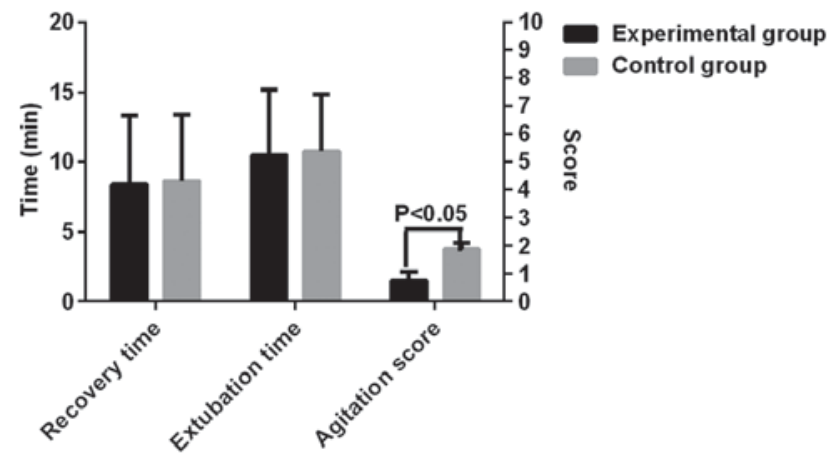

Figure 5. Comparison of post-anesthesia recovery in the two groups of children. There was no difference in extubation time between the two groups $(\mathrm{p}>0.05)$. Agitation was more severe in the control group than in the experimental group $(\mathrm{p}<0.05)$.

significant effect on relieving respiratory depression after the induction of general anesthesia. According to literature, the sedative effect of Dex does not impact spontaneous breathing (26). Dex exerts a mild analgesic effect and induces natural non-eye-movement sleep by agonizing $\alpha$-adrenergic receptors in the brainstem locus coeruleus. Subjects in this sedated state can still be awakened (27). We think that this excitatory mechanism may not impact the vagal tone, and thus, it avoids the suppression signal from the respiratory control center in the medulla oblongata. In a word, Dex avoids perioperative respiratory depression from the port.

In terms of hemodynamics, our results showed that HR and MAP values from T1 to T4 were all lower than those at T0 in both the experimental and control groups. HR values in the experimental group were obviously higher than those at the same time-point in the control group. Compared with the control group, MAP value was lower at T2, but higher at T1-T4 in the experimental group. MAP values in the experimental group fluctuated within a smaller range compared with those in the control group, suggesting that Dex can counter abnormal decreases of heart rate and blood pressure caused by other drugs, thereby stabilizing hemodynamic parameters. According to literature, slow pump infusion of Dex can prevent activation of the q receptors located in the vascular smooth muscle, thereby relieving vasoconstriction (28). In addition, Dex can also counter abnormal increases of blood pressure and heart rate caused by stimulation of other drugs of the sympathetic nerves due to its inhibitory effect on sympathetic nerve activity (29). Our findings suggested that Dex can inhibit the release of catecholamines by acting on $\alpha$ receptors, thereby attenuating the physiological effects of catecholamines such as increases in myocardial contractility, cardiac stroke volume, and heart rate (30). In this way, Dex stabilizes intraoperative hemodynamics.

Analysis of post-anesthesia resuscitation showed no significant difference in both the recovery and extubation time between the two groups, but agitation was more severe in the control group than in the experimental group. Clinical studies have shown that children are often prone to anxiety and confusion after anesthesia. It has been reported that Dex can reduce the incidence of mental confusion in children (31). Compared with other commonly used sedative drugs such as Mita, Dex reduces the incidence of postoperative agitation in children (32). In the pediatric strabismus anesthesia for the same eye surgery, it has been reported that (33) intraoperative low-dose injection of Dex can reduce the frequency of fentanyl rescue, and the maximum value of intraoperative anxiety and discussion scores are smaller than those in the normal saline group. These studies have shown that Dex may significantly improve postoperative agitation in children.

In this study, the effect of Dex on respiratory function in pediatric patients undergoing RB resection was explored. In our future studies, interaction between multiple anesthetic sedatives will be considered. Animal models will also be established to explore the underlying mechanism. This study did not include the prognosis of respiratory function in children with RB, which should also be included in our future studies.

In summary, Dex can decrease surgical difficulties and increase anesthetic safety by improving the respiratory function and maintaining hemodynamic stability during anesthesia induction in children undergoing $\mathrm{RB}$ resection, so as to reduce surgical difficulty and increase anesthesia safety.

\section{Acknowledgements}

Not applicable.

\section{Funding}

No funding was received.

\section{Availability of data and materials}

The datasets used and/or analyzed during the current study are available from the corresponding author on reasonable request.

\section{Authors' contributions}

$\mathrm{XR}$ and $\mathrm{CS}$ recorded and analyzed indexes of respiratory function and hemodynamics. FZ and JZ were responsible for anesthetic procedures. All authors read and approved the final manuscript.

\section{Ethics approval and consent to participate}

This study was approved by the Ethics Committee of Yidu Central Hospital of Weifang (Weifang, China). Parents of the child patients who participated in this research signed an informed consent and the children had complete clinical data.

\section{Patient consent for publication}

Not applicable.

\section{Competing interests}

The authors declare that they have no competing interests.

\section{References}

1. Schlößer HA, Drebber U, Kloth M, Thelen M, Rothschild SI, Haase S, Garcia-Marquez M, Wennhold K, Berlth F, Urbanski A, et al: Immune checkpoints programmed death 1 ligand 1 and cytotoxic T lymphocyte associated molecule 4 in gastric adenocarcinoma. OncoImmunology 5: e1100789, 2015. 
2. Kamihara J, Ma C, Fuentes Alabi SL, Garrido C, Frazier AL, Rodriguez-Galindo C and Orjuela MA: Socioeconomic status and global variations in the incidence of neuroblastoma: call for support of population-based cancer registries in low-middle-income countries. Pediatr Blood Cancer 64: 321-323, 2017.

3. Friedman DL, Krailo M, Villaluna D, Gombos D, Langholz B, Jubran R, Shields C, Murphree L, O'Brien J, Kessel S, et al: Systemic neoadjuvant chemotherapy for Group B intraocular retinoblastoma (ARET0331): a report from the Children's Oncology Group. Pediatr Blood Cancer 64: e26394, 2017.

4. Kelly KR, DeSimone KD, Gallie BL and Steeves JK: Increased cortical surface area and gyrification following long-term survival from early monocular enucleation. Neuroimage Clin 7 : 297-305, 2014

5. Dimaras H, Corson TW, Cobrinik D, White A, Zhao J, Munier FL, Abramson DH, Shields CL, Chantada GL, Njuguna F, et al: Retinoblastoma. Nat Rev Dis Primers 1: 15021, 2015.

6. Chantada G and Schaiquevich P: Management of retinoblastoma in children: current status. Paediatr Drugs 17: 185-198, 2015.

7. Mathew AA, Sachdev N, Staffieri SE, McKenzie JD and Elder JE: Superselective intra-arterial chemotherapy for advanced retinoblastoma complicated by metastatic disease. J AAPOS 19: 72-74, 2015.

8. Gomez de Agüero M, Ganal-Vonarburg SC, Fuhrer T, Rupp S, Uchimura Y, Li H, Steinert A, Heikenwalder M, Hapfelmeier S, Sauer U, et al: The maternal microbiota drives early postnatal innate immune development. Science 351: 1296-1302, 2016.

9. Taenzer A, Walker BJ, Bosenberg AT, Krane EJ, Martin LD, Polaner DM, Wolf C and Suresh S: Interscalene brachial plexus blocks under general anesthesia in children: is this safe practice?: a report from the Pediatric Regional Anesthesia Network (PRAN). Reg Anesth Pain Med 39: 502-505, 2014.

10. Davis PJ and Cladis FP: Smith's Anesthesia for Infants and Children (e-book). 9th edition. Elsevier, Philadelphia, 2017.

11. Wang X, Zhao B and Li X: Dexmedetomidine attenuates isoflurane-induced cognitive impairment through antioxidant, anti-inflammatory and anti-apoptosis in aging rat. Int J Clin Exp Med 8: 17281-17288, 2015

12. Sankar A, Johnson SR, Beattie WS, Tait G and Wijeysundera DN Reliability of the American Society of Anesthesiologists physical status scale in clinical practice. Br J Anaesth 113: 424-432, 2014

13. Akbulut UE, Saylan S, Sengu B, Akcali GE, Erturk E and Cakir M: A comparison of sedation with midazolam-ketamine versus propofol-fentanyl during endoscopy in children: a randomized trial. Eur J Gastroenterol Hepatol 29: 112-118, 2017.

14. Bellolio MF, Puls HA, Anderson JL, Gilani WI, Murad MH, Barrionuevo P, Erwin PJ, Wang Z and Hess EP: Incidence of adverse events in paediatric procedural sedation in the emergency department: a systematic review and meta-analysis. BMJ Open 6: e011384, 2016.

15. Bong CL, Lim E, Allen JC, Choo WL, Siow YN, Teo PB and Tan JS: A comparison of single-dose dexmedetomidine or propofol on the incidence of emergence delirium in children undergoing general anaesthesia for magnetic resonance imaging. Anaesthesia 70: 393-399, 2015.

16. de Jong MC, de Graaf P, Brisse HJ, Galluzzi P, Göricke SL, Moll AC, Munier FL, Popovic MB, Moulin AP, Binaghi S, et al; European Retinoblastoma Imaging Collaboration (ERIC): The potential of 3T high-resolution magnetic resonance imaging for diagnosis, staging, and follow-up of retinoblastoma. Surv Ophthalmol 60: 346-355, 2015.

17. Kim JY and Park Y: Treatment of retinoblastoma: The role of external beam radiotherapy. Yonsei Med J 56: 1478-1491, 2015.

18. Lerman J, Coté CJ and Steward DJ: Manual of pediatric anesthesia. Springer, New York, NY, 2016.

19. Baradari AG, Alipour A, Habibi MR, Rashidaei S and Emami Zeydi A: A randomized clinical trial comparing hemodynamic responses to ketamine-propofol combination (ketofol) versus etomidate during anesthesia induction in patients with left ventricular dysfunction undergoing coronary artery bypass graft surgery. Arch Med Sci 13: 1102-1110, 2017.
20. Andolfatto G, Abu-Laban RB, Zed PJ, Staniforth SM, Stackhouse S, Moadebi S and Willman E: Ketamine-propofol combination (ketofol) versus propofol alone for emergency department procedural sedation and analgesia: a randomized double-blind trial. Ann Emerg Med 59: 504-512.e501-502, 2012

21. Xiao F, Xu WP, Zhang YF, Liu L, Liu X and Wang LZ: The dose-response of intrathecal ropivacaine co-administered with sufentanil for cesarean delivery under combined spinal-epidura anesthesia in patients with scarred uterus. Chin Med J (Engl) 128: 2577-2582, 2015

22. Youssef N, Orlov D, Alie T, Chong M, Cheng J, Thabane L and Paul J: What epidural opioid results in the best analgesia outcomes and fewest side effects after surgery?: a meta-analysis of randomized controlled trials. Anesth Analg 119: 965-977, 2014.

23. Zhang H, Yan X, Wang DG, Leng YF, Wan ZH, Liu YQ and Zhang Y: Dexmedetomidine relieves formaldehyde-induced pain in rats through both $\alpha 2$ adrenoceptor and imidazoline receptor. Biomed Pharmacother 90: 914-920, 2017.

24. Julien C, Oréa V, Quintin L, Piriou V and Barrès C: Renal sympathetic nerve activity and vascular reactivity to phenylephrine after lipopolysaccharide administration in conscious rats. Physiol Rep 5: 5, 2017.

25. Song J, Ji Q, Sun Q, Gao T, Liu K and Li L: The opioid-sparing effect of intraoperative dexmedetomidine infusion after craniotomy. J Neurosurg Anesthesiol 28: 14-20, 2016.

26. Sato N, Saiki C, Tamiya J, Imai T and Sunada K: Imidazoline 1 receptor activation preserves respiratory drive in spontaneously breathing newborn rats during dexmedetomidine administration. Paediatr Anaesth 27: 506-515, 2017.

27. Kim DJ, Kim SH, So KY and Jung KT: Effects of dexmedetomidine on smooth emergence from anaesthesia in elderly patients undergoing orthopaedic surgery. BMC Anesthesiol 15: 139, 2015.

28. Li Q, Chen C, Chen X, Han M and Li J: Dexmedetomidine attenuates renal fibrosis via $\alpha 2$-adrenergic receptor-dependent inhibition of cellular senescence after renal ischemia/reperfusion. Life Sci 207: 1-8, 2018.

29. Mandal D, Das A, Chhaule S, Halder PS, Paul J, RoyBasunia S, Chattopadhyay S and Mandal SK: The effect of dexmedetomidine added to preemptive ( $2 \%$ lignocaine with adrenaline) infiltration on intraoperative hemodynamics and postoperative pain after ambulatory maxillofacial surgeries under general anesthesia. Anesth Essays Res 10: 324-331, 2016.

30. Mikami M, Zhang Y, Kim B, Worgall TS, Groeben H and Emala CW: Dexmedetomidine's inhibitory effects on acetylcholine release from cholinergic nerves in guinea pig trachea: a mechanism that accounts for its clinical benefit during airway irritation. BMC Anesthesiol 17: 52, 2017.

31. Whitman TM: Emergence delirium in children: review and rationale for the use of dexmedetomidine for prevention. J Pediatr Surg Nurs 7: 41-46, 2018.

32. Pasin L, Febres D, Testa V, Frati E, Borghi G, Landoni G and Zangrillo A: Dexmedetomidine vs midazolam as preanesthetic medication in children: a meta-analysis of randomized controlled trials. Paediatr Anaesth 25: 468-476, 2015.

33. Kim J, Kim SY, Lee JH, Kang YR and Koo BN: Low-dose dexmedetomidine reduces emergence agitation after desflurane anaesthesia in children undergoing strabismus surgery. Yonsei Med J 55: 508-516, 2014.

This work is licensed under a Creative Commons Attribution-NonCommercial-NoDerivatives 4.0 International (CC BY-NC-ND 4.0) License. 